\title{
Research on China Transnational Corporations Environmental Responsibility on the B\&R
}

\author{
Xie, Wei ${ }^{1, a}$ \\ ${ }^{1}$ Laws College, Guangdong University of Finance \& Economics, Guangzhou, China \\ 18927527246@163.com
}

Keywords: the Belt and Road, Transnational Corporations, Environmental Responsibility

\begin{abstract}
In order to promote the Belt and Road (B\&R) construction, China TNCs should undertake more environmental responsibilities including ten core ones: Environment pollution prevention, Natural resources protection, Clean production, Development of green energy, energy conservation, reducing energy and resource consumption, Conservation of biological diversity, Green R \& D, Promotion and transfer of advanced environmental technology, Financing environmental public interest activity, Green product, and Raising environmental awareness and promoting public participation. China TNCs should establish their own environmental responsibility index system, develop their own environmental technology reference to developed countries' environmental laws, regulations and standards. China government must take practical actions to support TNC so as to fulfill their environmental responsibility and the NGOs should become the effective supervision force.
\end{abstract}

\section{Introduction}

The Belt and Road must become the green development. Transnational Corporations (Hereinafter referred to as TNCs) play important roles in the Belt and Road construction. Nowadays, if TNCs want to make profits in the Belt and Road, they have to undertake more environmental responsibilities under the sustainable development background. The developed countries mainly study the Corporation Environment Responsibility (Hereinafter referred to as CER) index evaluation system, implementation mechanisms, detailed content. etc. The related research in China has also been started, which includes general introduction to CER, the importance and value of CER, the content and evaluation index system.CER of TNC is the key element of Corporation Social Responsibility (Hereinafter referred to as CSR).

Environmental Responsibilities that China TNCs should undertake on the B\&R.

Pollution Prevention. As the main pollution producer, TNCs should bear the statutory obligation to prevent and control the environment pollution. The idea of Risk control should be established, that is prevention priority, and then to combine prevention with control.

Clean Production. The clean production responsibility means that TNCs should take full-process control, from the origin to the end including product design, production and consumption, adhering to the idea of prevention priority, to protect the environment and save resource, in order to achieve the green development on the B\&R.

Natural Resources Protection. Natural Resources means that all kinds of natural elements which are useful to human under the special economic and technological conditions. The sustainable development is inseparable from the natural resources, so the obligation to protect the natural resource must be given to $\mathrm{TNCs}$ for their damages to the natural resources in the process of production.

Green Energy. China TNCs should implement green energy strategy, which will include exploiting green energy, saving energy, and reducing energy and resource consumption. Energy conservation and rational exploitation is closely related with environment and resource protection. The environment problems from the energy exploitation are mainly reflected as pollution and nature damage. China TNCs should become the subjects to develop and use green energy, whose duties will 
be the following as: reducing production energy consumption; developing alternative energy and renewable energy, inventing energy-efficient products, eliminating high energy consumption products, and so on.

Conservation of Biological Diversity. It is the key reason of lots of species extinction that TNCs have made predatory exploitation to worldwide biodiversity resources. As a result, TNCs must bear the responsibility to protect biodiversity, which should include following as: protecting original ecology, forbidding to buy, transport, sell, carry endangered wildlife, and so on..

Green R \& D. Science and technology has been proved as primary productive force by economic development practice, as a result, TNCs must promote Research and Development (R\&D) of environment technology, and provide the enough finance for green R \& D.

Transfer of Advanced Environment Technology. Because China TNCs will carry out exploitation to the natural resources of the B\&R countries, they should transfer advanced environment technology to them. Otherwise, the exploitation is not sustainable. In order to promote sustainable development, China TNCs should bear such obligations.

Funding Environment Public Interest Activity. The B\&R construction must be based on the environment resources, but environment protection needs a lots of funds. Obviously, only financial support of the developing countries cannot meet the needs of environment protection, while China TNCs will make profits from the B\&R. As a result, China TNCs should take out part of their profits to support environment public interest activities.

Green Product. Green trade has effectively promoted the rise of green consumption, which marks with green products had become the leading in international trade. China TNCs should produce green products and promote green market, that is to develop recycled products with small pollution to environment by means of advanced environment technology. On the $B \& R$, who have green products, who will control the market.

Public Participation. To promote the public participation, China TNCs should initiatively publish their environment information, invite the public in the environment impact assessment, facilitate the participation procedure, and accept the public scrutiny and criticism.

\section{CER Status of China TNCs}

In 1995, Sinopec joined the World Business Council for Sustainable Development (WBCSD)[1]. In 1999, the "Global Compact" required that TNCs should value the labor standards, human rights and environmental protection[2]. China also joined the Global Compact Action Plan. In October, 2003, the Trade and Industry Commission on Sustainable Development of China Enterprise Confederation was established formally. Some well-known, large-scale Chinese state-owned enterprises joined the organization, such as the China National Petroleum Corporation, China National Offshore Oil Corporation, China Petroleum \& Chemical Corporation, etc. In 2016, Chinese Corporate Social Responsibility Blue Book was published, which was the eighth announcement successively. A lot of China TNCs have provided their own CER ideas, for example, China National Petroleum Corporation established its own CER core idea as"creating energy harmony with the environment."[3] But generally speaking, there are still many China TNCs lacking the awareness of environmental responsibility and practical actions. With the rapid development of the $\mathrm{B} \& \mathrm{R}$, the countries along the B\&R also strengthened the CER requirements to China TNCs. For example, China home appliance TNCs were required to take environmental responsibility in EU market, ie they must be responsible for recycling all the old home appliances sold in the EU, and pay the relevant expenses [4].

It is difficult for enterprises to pay the huge environmental damage compensation, while the government has to pay the bill. On the contrary, environmentally friendly business has access to a huge space for development. For example, because of the impact of the subprime crisis, U.S. housing prices have been falling recently, the industry was expected to sell only 632,000 new houses in 2009, which was the lowest since 1992, but the demand for green house that can reduce daily energy expenditure has risen against the tide. Such as ICYNENE, the famous brand of Green housing industry, its performance of every year on average increased by $22 \%$ in the past three years [5]. So, 
TNCs should initiatively bear CER, which is the need of their own survival and development, the inevitable choice under the fierce competition, and the necessary requirements of every country along the B\&R to strictly implement environment laws and regulations.

\section{How to Improve China TNCs CER.}

Constructing China TNCs CER Realization Mechanism. In the report of the 18th national congress of CPC, President Hu Jintao, the General Secretary of CPC Central Committee, stressed to speed up the pace of going out, enhance the internationalization of enterprises, and cultivate a number of world-class multinational companies [6]. Thus, the basis for the development of China TNCs has been formally established. China TNCs must fulfill their CER adapting to their economic strength.

Government Requiring and Supporting the State-Owned Enterprises to Perform CER. China TNCs always consist of state-owned enterprises as the main component. As a result, the impact of the government is crucial for enterprise development. The government should firstly fufill corresponding environment supervision responsibility. For effective implementation of CER, China government must conduct the following three fundamental reforms:

Comprehensive Official Performance Evaluation Index System. One-sided using the growth of GDP to evaluate officials performance is one of the fundamental reasons causing environmental pollution and resources damage. Attaching to the government, the leaders of large state-owned enterprises are also classified as "government officials" according to administrative levels, who also have to pursue one-sided economic interests of enterprises growth, so ignore CER that the companies should undertake. Evaluating officials performance should not only depend on the economic growth indicators, but also the comprehensive strength, and not only the fixed target, but also the soft power, not only the profits, but also the development value and potential growth space of enterprise.

Regulation Mode of Balance of Powers. Altering power highly centralized control style, the government should not regulate the corporation to fulfill CER both as a "player" and a "trainer". The independent government service should be established, whose main task is to supervise TNCs fulfilling CER. China government should take advantage of the superior dominant that socialism can concentrate power to get big jobs done, rapidly increase the capacity of enterprises to fulfill their environmental responsibilities.

Government Environmental Regulatory Accountability. Changing the original accountability mechanisms of government officials, the government should effectively fulfill environmental regulatory responsibility. For the serious environmental accidents resulted from the corporation, not only the corporate should be accountable, but also the government officials should be accountable. Under the provisions of administrative law accountability, the related officials should be strictly treated and punished, never be indulged.

Building Evaluation System of CER. At present, the developed countries have established the evaluation index system for TNCs to fulfill CER. By learning from developed countries, the CER evaluation system with Chinese characteristics should be established, including government supervision and control, industry self-regulation, corporate consciousness, public participation, and so on. In 2005, the State Council had approved to develop CSR of China led by the Ministry of Commerce, together with seven ministries, but up to now, China has not promulgate CSR with Chinese characteristics. There are more than four hundred corporate social responsibility standards in the world, including the code of production, yet no one is established by China, which is very negative for Chinese enterprises to participate in international competition[7]. On November 22, 2008, the former China President Hu Jintao said in the meeting of APEC informal leadership that companies should establish the concept of global responsibility, initiatively put social responsibility into business strategy, respect the local laws and internationally accepted business customary, improve the business model in order to pursue the unity of economic and social interests [8]. On March 7,2017, the China President Xi Jinping also said in the meeting of Liaoning Delegation of the fifth Session of the $12^{\text {th }}$ National People's Congress that state-owned enterprises should fulfill the CSR exemplarily and become the enterprise citizen model. [9]

Improving Environment Responsibility Competitiveness of Enterprise. The corporate environmental responsibility competitiveness is the comprehensive concept, which should cover the 
brand, management, culture and other aspects, what the enterprises have formed according to their environmental performances. The competitiveness of enterprises can be found in each stage, including corporate product producing, product quality control power, business services, cost control, marketing, R \& D capability. CER should be embodied in all links of product chain. Enhancing the competitiveness of corporate environment responsibility can promote the efficient use and recycling of resources, so as to achieve reduction, reuse, recycling and ultimately meet the low consumption, low emission and high efficiency, which is consistent with sustainable development. With the full support of the Government and on its own strength, CER of China TNCs can be improved by means of their R \& D capabilities to advanced environmental technology.

Public Participating in Monitoring CER. The practice has proved that the most effective method for TNCs to fulfill their CER is the government supervision under the public participation, which should include three major areas:

Building and Improving the organization law of environmental NGOs. The practice of developed countries has proved, the appropriate settlement mechanism is to rely on the third force because both the government failure and the market failure may exist in the field of environmental protection, that is environmental protection non-governmental organizations and other social forces. China lacks the cultural origins of civil society and organization basis, with inadequate modern legal system, what makes the third force lack the legal basis as well as the absence of ideological and cultural basis to promote them development. It must be recognized that promoting environmental non-governmental organizations to develop should become one of the most favorable supervision mechanisms to ensure the enterprises to fulfill CER.

Building and Improving Environment Information Disclosure Mechanism. At present, China government has formulated and promulgated the "Regulation to Open Government Information", but for corporate environmental information disclosure, China government has not yet issued mandatory laws or regulations. It should be clear that the environment contamination risk information must be published for the public, except the information involved in company intellectual property and trade secret. The public needs both the government and enterprise environment information. The public can analyze, predict, assess whether the company production may have the potential impact on the environment and thus supervise enterprises CER.

Constructing and Improving the Environmental NGOs Finance System. Currently, China environmental NGOs are not short of human resources, but short of funds. A few influential Environmental NGOs can get some funds mainly from the government. Most grassroots social groups lack the necessary funds, so that they cannot supervise the enterprises to fulfill their CER. So the good financial support mechanism must be constructed for the environmental NGOs. First is the government should build the special NGOs development fund. The second is to encourage the society to donate for NGOs. The third is to permit the NGOs can conduct some business activities consistent with its purpose, what get from the business can make up the public environmental interests activities.

\section{Conclusion}

It is a necessary requirement for China TNCs to fulfill their CER in the B\&R construction, and it is also essential for their own survival and development. At present, China TNCs need build and improve the CER accountability and compliance mechanisms by means of the government support, the enterprises themselves, and the public participation. The Government must reform the original performance evaluation index system for the officials, which should be replaced by a comprehensive evaluation indicator system of sustainable development. The government must alter the high centralized supervision mode, which should be replaced by regulation mode of the balance of powers; The government must alter the accountability mechanisms of government officials, which should be replaced by the implementation of government environmental regulatory accountability. For themselves, China TNCs should learn from the experience of developed countries TNCs, build CER evaluation system; improve their environmental competitiveness by means of their own R \& D for advanced environmental technology. For the public participation, the Chinese government should 
quickly build and improve the environmental NGO's organizational law, environmental NGO's financing system, as well as government and business environmental information disclosure mechanisms.

\section{Acknowledgements}

This work was financially supported by Sino-US corporative research group of Ecological Culture Legal Systems Construction of Guangdong University of Finance \& Economic and Pace University, which is one of the foreign exchange and cooperative projects of the Thirteenth Five-Year Innovative School Project of Guangdong University of Finance \& Economic.

\section{References}

[1] Zou Jing. World Business Council for Sustainable Development. World Environment. Vol. 6(2005), p.95.(in Chinese)

[2] United Nations Conference on Trade and Development.Investment and Enterprise Responsibility Review: Analysis of Investor and Enterprise Policies on Corporate Social Responsibility, the United Nations, 2010.

[3] China National Petroleum Corporation. Service Concept of Civilization,2010 (in Chinese).

[4] Wang Yuxin, Jiang Yihang. Implementation of EU Environmental Protection Order 1/3 of China's Household Electrical Appliance Enterprises Maybe Give Up the European Market, China Economic Times,2006.(in Chinese)

[5] Hu Jintao. Report of the Eighteenth Congress of the Communist Party of China, People's Publishing House,2012. (in Chinese)

[6] Li Liangyong. Green Housing: Low Investment and High Consumption, Xinmin Evening News June, 13:A34,2008. (in Chinese)

[7] Xinhua News Agency. Report of Sixty Years of Corporate Social Responsibility in China,2009. (in Chinese)

[8] Qian Tong, Chen Hegao, the Second Phase of the Sixteenth Session APEC Informal Leadership Meeting President Hu Jintao to Attend and Speak. News Agency, November,24, 2008. (in Chinese)

[9] Wu Yang. Xi Jinping Hope the State-Owned Enterprises to Do the Same, http://news.youth.cn/sz/201703/t20170324_9347272.htm, March 24, 2017. 